\title{
Bài báo khoa học \\ Ảnh hưởng của sóng trong bão tới ngập lụt vùng ven biển tỉnh Thái Bình
}

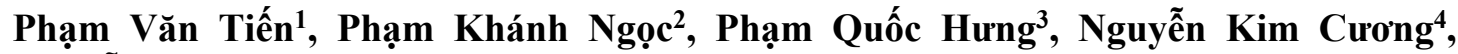 \\ Nguyễn Bá Thủ ${ }^{2 *}$
}

${ }^{1}$ Viện Năng Lượng, Bộ Công Thương; phamvantienbn@gmail.com

2 Trung tâm Dự báo khí tượng thủy văn quốc gia; ngocpkchibo@gmail.com; thuybanguyen@gmail.com

${ }^{3}$ Đài Khí tượng Thủy văn tỉnh Thái Bình; quochungkttv@gmail.com

${ }^{4}$ Trường Đại học Khoa học Tự nhiên, Đại học Quốc gia Hà Nội; cuongnk@hus.edu.vn

* Tác giả liên hệ: thuybanguyen@gmail.com; Tel.: +84-975853471

Ban Biên tập nhận bài: 15/2/2021; Ngày phản biện xong: 28/3/2021; Ngày đăng bài: $25 / 4 / 2021$

Tóm tắt: Sóng và nước dâng trong bão/áp thấp nhiệt đới là những hiện tượng thiên tai đặc biệt nguy hiểm, có tác động lớn đến các công trình và ngành kinh tế ven biển. Đặc biệt, khi bão đổ bộ vào thời điểm triều cường, sự kết hợp giữa sóng, nước dâng và thủy triều sẽ gây nên mực nước tổng cộng lớn làm ngập lụt và xói lở bờ biển, phá hủy nhiều công trình ven biển. Ngập lụt vùng ven bờ biển khi bão đổ bộ phụ thuộc vào địa hình khu vực (trên cạn và dưới nước), thủy triều, nước dâng do bão và nước dâng do sóng. Chính vì vậy, mô hình dự báo ngập lụt ven bờ cần thiết phải tính đến đồng thời ảnh hưởng của thủy triều, nước dâng do bão và sóng. Ngoài ra, địa hình khu vực ven bờ cần thiết phải có độ phân giải chi tiết và có xét tới hệ thống đê biển. Mô hình tích hợp thủy triều, sóng và nước dâng bão SuWAT (surge wave and tide) được phát triển tại đại học Kyoto Nhật Bản, đã và đang được áp dụng trong dự báo nước dâng bão tại nhiều nơi trên thế giới trong đó có Trung tâm dự báo khí tượng thủy văn quốc gia. Trong nghiên cứu này, tác giả sẽ trình bày các kết quả nghiên cứu mô phỏng ngập lụt trong bão tại ven biển Thái Bình trong một cơn bão quá khứ và với các kịch bản bão giả định. Nghiên cứu sẽ là cơ sở để tiến tới ứng dụng mô hình SuWAT trong cảnh báo, dự báo nghiệp vụ ngập lụt cho vùng biển ven bờ Việt Nam.

Từ khóa: Nước dâng do bão; Ngập lụt; Nước dâng do sóng; SuWAT.

\section{Mở đầu}

Ven biển Thái Bình thuộc Đồng Bằng Bắc Bộ cũng là nơi thường xuyên bị ảnh hưởng của bão và áp thấp nhiệt đới. Tại khu vực ven biển này, lịch sử đã ghi nhận nhiều cơn bão mạnh gây nước biển dâng, sóng lớn và ngập lụt ven bờ trên diện rộng như bão Frankie (7/1996), Niky (8/1996), Washi (7/2005), Damrey (9/2005), Sơn Tinh (10/2012), Kalmaegy (9/2014), Mirinae (7/2016), Doksuri (9/2017). Thủy triều ven biển Thái Bình có biên độ lớn, nước dâng do bão đặc biệt nguy hiểm khi xuất hiện vào đúng thời kỳ triều cường, mực nước tổng cộng dâng cao, kết hợp với sóng to có thể tràn qua đê vào khu đô thị, đồng ruộng, đây chính là nguyên nhân gây thiệt hại nặng nề về người và của. Đã có nhiều cơn bão ảnh hưởng tới khu vực đúng vào kỳ triều cường như bão Washi (7/2005), Damrey $(9 / 2005)$, Sơn Tinh (10/2012), Kalmaegy (9/2014), Doksuri (9/2017). Vùng ven biển Thái Bình đang là trọng điểm phát triển kinh tế của tỉnh, khu vực này từ lâu là nơi tập trung các hoạt động nuôi trồng 
thủy hải sản có quy mô lớn. Hiện nay khu vực cũng là nơi tập trung lớn các khu, cụm công nghiệp, cảng biển, cảng sông, các nhà máy nhiệt điện; khu vực Cồn Đen, Cồn Vành hiện nay đang là những khu du lịch nghỉ dưỡng thu hút rất nhiều khách trong và ngoài tỉnh. Tuy nhiên, cho tới hiện tại, các sản phẩm dự báo của Trung tâm Dự báo khí tượng thủy văn quốc gia và Đài Khí tượng Thủy văn khu vực đồng bằng Bắc Bộ chỉ dừng lại ở thông tin về độ lớn nước dâng và độ cao sóng tại khu vực, chưa có một công cụ dự báo ngập lụt do nước dâng kết hợp với thủy triều và sóng trong bão. Chính vì vậy, việc nghiên cứu và xây dựng mô hình dự báo nước dâng, sóng lớn do bão kết hợp với triều cường gây ngập lụt ven biển tỉnh Thái Bình là hết sức cần thiết và có ý nghĩa thực tiến, nhằm phục vụ hiệu quả cho phòng chống thiên tai và phát triển kinh tế xã hội khu vực ven biển tỉnh Thái Bình.

Hiện có nhiều phương pháp tính toán và dự báo nước dâng và sóng lớn do bão như phương pháp sử dụng các công thức bán thực nghiệm, phương pháp synop và phương pháp mô hình số trị. Trong đó phương pháp sử dụng mô hình số trị được đánh giá là phương pháp hiệu quả, đáng tin cậy và ổn định nhất mà không mất nhiều thời gian. Tại Việt Nam, nghiên cứu về nước dâng bão có xét tới ảnh hưởng của thủy triều đã được thực hiện bởi một số tác giả [1-6]. Nội dung chính của những nghiên cứu này chủ yếu tập trung đánh giá nước dâng khi bão đổ bộ vào các pha triều khác nhau. Ảnh hưởng của sóng biển tới nước dâng do bão gần đây đã được nghiên cứu. Nước dâng do ứng suất bức xạ sóng tính theo công thức bán kinh nghiệm là đáng kể tại ven biển Hải Phòng [7]. Một số nghiên cứu nước dâng do bão có xét tới ảnh hưởng của thủy triều và sóng bằng mô hình số trị tích hợp SuWAT được thực hiện bởi nhóm tác giả $[1,3,4,6,8-10]$. Mặc dù sử dụng lưới không gian có độ phân giải thô, tuy nhiên các nghiên cứu ở trên đều chỉ ra rằng sóng biển đóng góp một phần đáng kể tới nước dâng và ngập lụt ven bờdo bão. Tuy nhiên, nghiên cứu về ngập lụt khu vực ven biển do tác động của thủy triều, nước dâng do bão và nước dâng do sóng chưa được thực hiện. Ở nước ngoài, gần đây xu hướng sử dụng mô hình số trị có xét tới tương tác nước dâng, sóng và thủy triều (mô hình tích hợp) vào dự báo nước dâng do bão và ngập lụt ven biển đang được quan tâm do có nhiều ưu việt so với phương pháp truyền thống (chỉ xét tới tác động của gió và khí áp). Với mô hình tích hợp, tác động của sóng tới nước dâng bão được thể hiện qua ứng suất bề mặt do sóng và ứng suất bức xạ sóng tại vùng ven bờ. Với lớp biên mặt biển, ứng suất đã được thay thế bao gồm là hàm của cả tham số gió và sóng [11-12]. Một vài nghiên cứu đã kiểm tra tác động của ứng suất bề mặt do sóng cho thấy mô hình tích hợp đã cải thiện đáng kể kết quả tính toán nước dâng bão khi so với số liệu quan trắc [13-15]. Tại khu vực sát bờ, nước dâng do ứng suất bức xạ sóng cũng đã được nghiên cứu nhiều bằng mô hình tích hợp [13], [16-18]. Mô phỏng bằng mô hình kết hợp ADCIRC và SWAN cho thấy nước dâng do sóng có thể đóng góp từ 10-15\% vào mực nước dâng cực trị trong bão [13]. Trong cơn bão Katrina năm 2005 tại Hoa Kỳ, nước dâng do các hiệu ứng sóng ven bờ chiếm tới $80 \%$ mực nước dâng cực trị trong khi các ảnh hưởng khác như thủy triều, sóng bề mặt và nước dâng do gió chỉ đóng góp 20\% [19].

Mô hình tích hợp thủy triều, sóng và nước dâng bão SuWAT (Surge Wave And Tide) được phát triển tại đại học Kyoto-Nhật Bản [17, 20-21], đã và đang được áp dụng trong dự báo nước dâng bão tại nhiều nơi trên thế giới trong đó có Trung tâm Dự báo khí tượng thủy văn quốc gia. Trong nghiên cứu này, kết quả mô phỏng ngập lụt trong bão tại ven biển Thái Bình trong cơn bão Damrey (9/2005) và với các kịch bản bão giả định được thực hiện. Nghiên cứu sẽ là cơ sở để tiến tới ứng dụng mô hình SuWAT trong cảnh báo, dự báo nghiệp vụ ngập lụt cho vùng biển ven bờ Việt Nam.

\section{Giới thiệu mô hình SuWAT}

\subsection{Mô hìn thủy động lự học}

SuWAT là mô hình Couple dự tính đồng thời cả thủy triều, sóng biển và nước dâng do baõ. Mô hình này được xây dựng tại đại học Kyoto - Nhật Bản, bao gồm 2 mô hình thành 
phần là mô hình thủy triều và nước dâng dựa trên hệ phương trình nước nông 2 chiều có tính đến nước dâng do ứng xuất sóng và mô hình quen thuộc SWAN tính toán sóng. Hệ phương trình cơ bản của mô hình nước nông 2 chiều được mô tả như sau:

$$
\begin{gathered}
\frac{\partial \eta}{\partial t}+\frac{\partial M}{\partial x}+\frac{\partial N}{\partial y}=0 \\
\frac{\partial M}{\partial x}+\frac{\partial}{\partial x}\left(\frac{M^{2}}{d}\right)+\frac{\partial}{\partial y}\left(\frac{M N}{d}\right)+g d \frac{\partial \eta}{\partial x} \\
=f N-\frac{1}{\rho_{w}} d \frac{\partial P}{\partial x}+\frac{1}{\rho_{w}}\left(\tau_{S}^{x}-\tau_{b}^{x}+F_{x}\right)+A_{h}\left(\frac{\partial^{2} M}{\partial x^{2}}+\frac{\partial^{2} M}{\partial y^{2}}\right) \\
\frac{\partial N}{\partial t}+\frac{\partial}{\partial y}\left(\frac{N^{2}}{d}\right)+\frac{\partial}{\partial x}\left(\frac{N M}{d}\right)+g d \frac{\partial \eta}{\partial y} \\
=-f M-\frac{1}{\rho_{w}} d \frac{\partial P}{\partial y}+\frac{1}{\rho_{w}}\left(\tau_{S}^{y}-\tau_{b}^{y}+F_{y}\right)+A_{h}\left(\frac{\partial^{2} N}{\partial x^{2}}+\frac{\partial^{2} N}{\partial y^{2}}\right)
\end{gathered}
$$

Trong đó $\eta$ là mực nước bề mặt; $\mathrm{M}, \mathrm{N}$ là thông lượng trung bình theo độ sâu, theo hướng $\mathrm{x}$ và $\mathrm{y} ; \mathrm{F}$ là tham số coriolis; $\mathrm{P}$ là áp suất khí quyển; $\mathrm{d}$ là độ sâu tổng cộng $\mathrm{d}=\eta+\mathrm{h}$, với $\mathrm{h}$ là độ sâu mực nước lúc yên tĩnh; $A_{h}$ là hệ số khuếch tán rối theo phương ngang; $\rho_{w}$ là mật độ nước; $\tau_{b}, \tau_{s}$ là ứng suất đáy và ứng suất bề mặt; $F_{x}, F_{y}$ là ứng suất sóng được thêm vào để tạo nước dâng do sóng, được tính từ mô hình SWAN theo các công thức dưới đây:

$$
\begin{gathered}
F_{x}=-\frac{\partial S_{x x}}{\partial x}-\frac{\partial S_{x y}}{\partial y} ; F_{y}=-\frac{\partial S_{y x}}{\partial x}-\frac{\partial S_{y y}}{\partial y} \\
S_{x x}=\rho g\left[\frac{C_{g}}{C} \cos ^{2} \theta+\frac{C_{g}}{C}-\frac{1}{2}\right] E d \sigma d \theta \\
S_{x y}=S_{y x}=\rho g[\cos \theta \sin \theta] E d \sigma d \theta \\
S_{y y}=\rho g\left[\frac{C_{g}}{C} \sin ^{2} \theta+\frac{C_{g}}{C}-\frac{1}{2}\right] E d \sigma d \theta
\end{gathered}
$$

Các tham số tại các công thức (5) đến (7) được định nghĩa trong cơ sở lý thuyết của mô hình SWAN. Mô hình SuWAT được thiết lập tính toán trên lưới lồng với cấu trúc được minh họa như trên Hình 1.

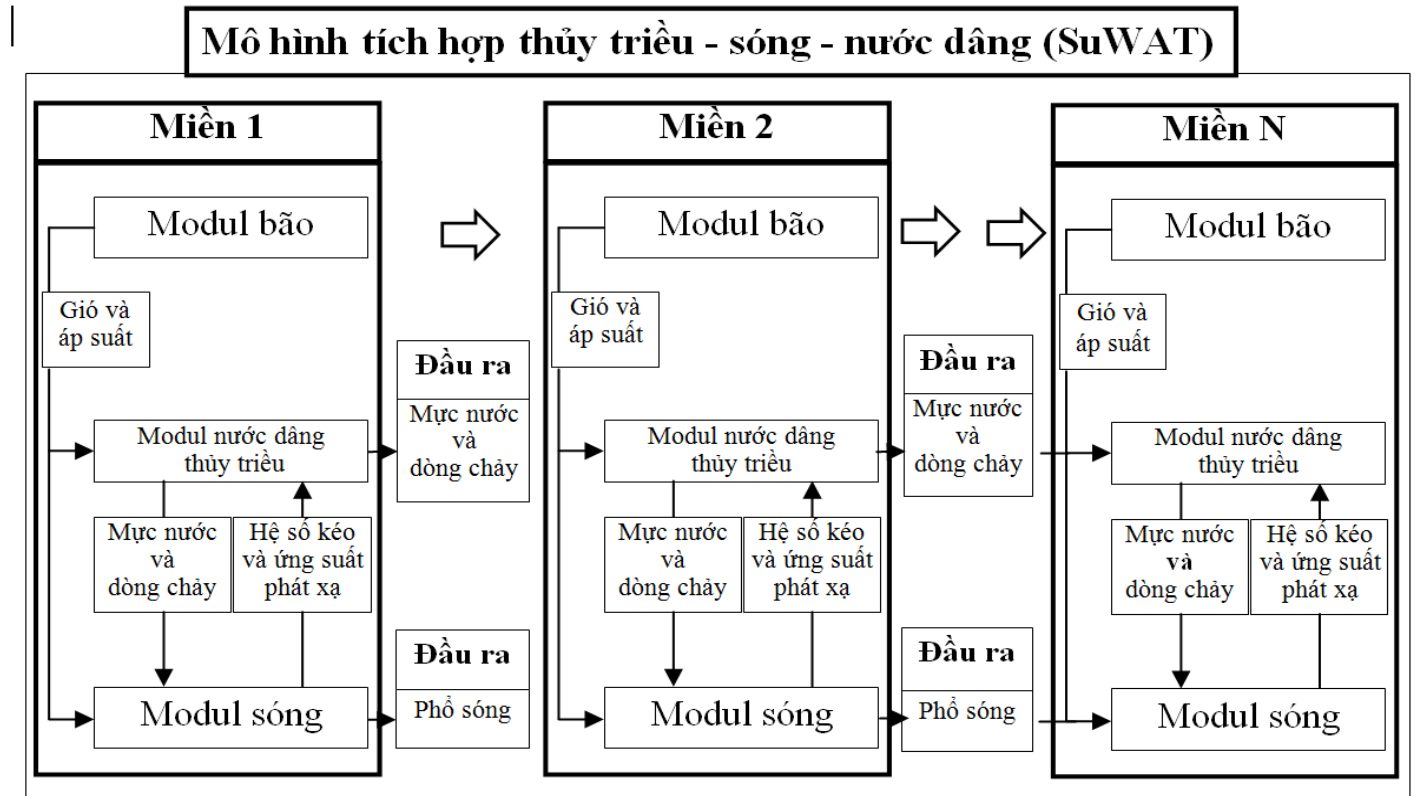

Hình 1. Cấu trúc lưới lồng của mô hình SuWAT. 


\subsection{Mô hình bão giải tích}

Mô hình SuWAT có thể nhận trường đầu vào gió, áp từ các mô hình bão giải tích và từ các mô hình dự báo số trị như WRF, HRM.... Trong nghiên cứu này, mô hình bão giải tích [17] được lựa chọn để mô phỏng trường gió. áp theo các tham số bão được lấy từ số liệu best track (https://www.jma.go.jp/jma/indexe.html). Trường áp suất khí quyển được tính theo công thức:

$$
P(r)=P_{\infty}-\frac{P_{\infty}-P_{c}}{\sqrt{1+\left(r / r_{0}\right)^{2}}}
$$

Trong đó $\mathrm{P}$ là Áp xuất ở tâm bão; $\mathrm{P}_{\infty}$ là áp xuất ở rìa bão; $\mathrm{r}_{0}$ là bán kính gió cực đại; $\mathrm{r}$ là khoảng cách từ tâm bão tới điểm tính.

Vận tốc gió gradien được tính theo mối liên hệ với phân bố của áp xuất khí quyển như trong công thức (8). Trong khi đó vận tốc gió theo mối liên hệ với tốc độ di chuyển của tâm bão được tính theo công thức (9).

$$
-\frac{v^{2}}{r}-f v=-\frac{1}{\rho} \frac{\partial P}{\partial r}
$$

$$
V_{F}=c_{2} V_{t} e^{-\frac{\pi r}{500}}
$$

Tổng hợp 2 thành phần này ta có vận tốc tổng hợp như sau:

$$
\boldsymbol{v}=\left(\begin{array}{l}
v_{x} \\
v_{y}
\end{array}\right)=c_{1}\left(\begin{array}{c}
-V_{g}(\sin \alpha \cdot \cos \theta+\cos \alpha \cdot \sin \theta) \\
V_{g}(\cos \alpha \cdot \cos \theta-\sin \alpha \cdot \sin \theta)
\end{array}\right)+c_{2}\left(\begin{array}{l}
v_{t x} \\
v_{t y}
\end{array}\right) e^{-\frac{\pi r}{500}}
$$

Trong đó giá trị các hệ số như sau: $\mathrm{c}_{1}=0,6 \div 0,8, \mathrm{c}_{2}=0,50 \div 0,8$.

\section{3. Ảnh hưởng của sóng đến ngập lụt ven biển Thái Bình trong bão}

\subsection{Miền tính và lưới tính cho mô hình}

Để có được sản phẩm dự báo với độ tin cậy cao, địa hình khu vực ven bờ cần thiết phải có độ phân giải chi tiết và có xét tới hệ thống đê biển, bao gồm lưới lồng 3 lớp (Hình 1). Hệ thống lưới lồng được xây dựng cho khu vực nhằm 3 mục đích: (1) có thể chi tiết hóa sự biến đổi phức tạp của địa hình khu vực ven bờ nhằm tăng độ chính xác của tính toán, (2) tăng khả năng tính nước dâng do sóng bởi nước dâng do sóng cần tính trên lưới có độ phân giải cao, (3) giảm thời gian tính toán. Miền tính và lưới tính cho các khu vực được mô tả chi tiết dưới đây:

- Lưới tính Biển Đông (lưới D1): đây là miền tính lớn nhất được xây dựng với độ phân giải ngang $5 \mathrm{~km}$ x $5 \mathrm{~km}$, bao phủ từ vĩ độ $0-25^{\circ} \mathrm{N}$, kinh độ $95-120^{\circ} \mathrm{E}$. Miền tính, trường độ sâu của các lưới $\mathrm{D} 1, \mathrm{D} 2$ và $\mathrm{D} 3$ được thể hiện trên Hình 2.

- Lưới lồng kế tiếp (lưới tính khu vực-D2): lưới tính D2 được thiết lập cho vùng biển Vịnh Bắc Bộ, với cùng độ phân giải 1 phút (khoảng $1850 \mathrm{~m}$ ), bao phủ từ vĩ độ $18,0-22,0^{\circ} \mathrm{N}$, $105,0-108,0^{\circ} \mathrm{E}$.

- Lưới lồng thứ 3 (lưới địa phương-D3): lưới tính D3 được thiết lập cho khu vực ven biển Thái Bình với độ phân giải cao $300 \mathrm{~m} \times 300 \mathrm{~m}$, miền tính bao phủ từ $20,23-20,72^{\circ} \mathrm{N}$, $106,40-106,75^{\circ} \mathrm{E}$.

Trên Bảng 1 mô tả thông tin chi tiết về miền tính, số điểm lưới và độ phân giải của các lưới tính cho khu vực ven biển Thái Bình.

Bảng 1. Thông tin về miền tính và lưới tính cho khu vực biển Thái Bình.

\begin{tabular}{ccc}
\hline Lưới & Miền tính & Độ phân giải $(\Delta \mathrm{x} \times \Delta \mathrm{y})$ \\
\hline D1 & $95^{\circ}-125^{\circ} \mathrm{E}, 0^{\circ}-25^{\circ} \mathrm{N}$ & $5000 \times 5000$ \\
D2 & $105,0^{\circ}-108,0^{\circ} \mathrm{E}, 18,0^{\circ}-22,0^{\circ} \mathrm{N}$ & $1850 \times 1850$ \\
D3 & $106,40^{\circ}-106,75^{\circ} \mathrm{E}, 20,23^{\circ}-20,72^{\circ} \mathrm{N}$ & $300 \times 300$ \\
\hline
\end{tabular}




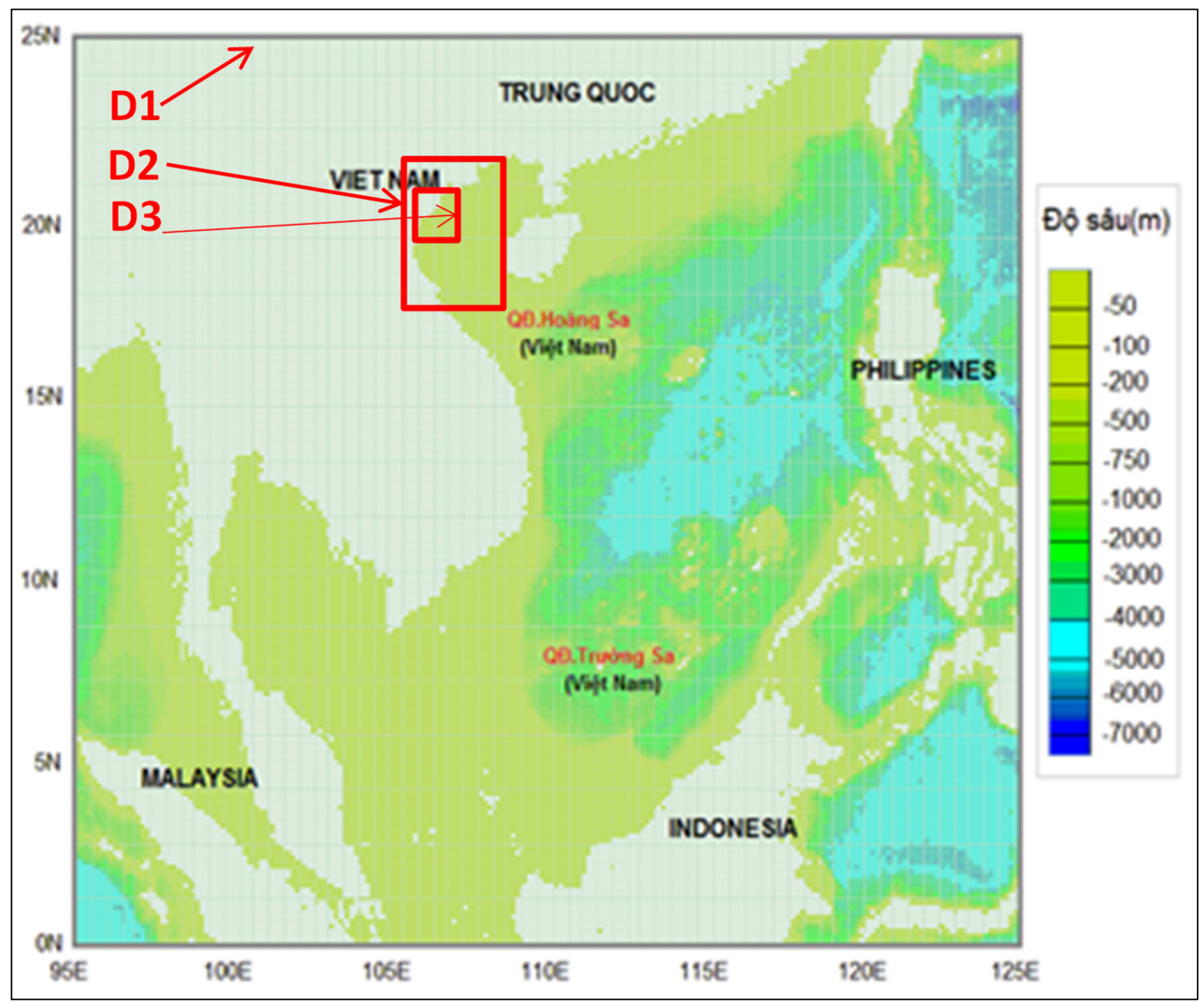

Hình 2. Miền tính và trường độ sâu của lưới $\mathrm{D} 1, \mathrm{D} 2$ và $\mathrm{D} 3$.

\subsection{Mô phỏng ngập lụt ven biển Thái Bình}

Việc hiệu chỉnh và kiểm định mô hình SuWAT, cũng như mô hình bão giải tích đã được thực hiện và trình bày nhiều lần trong các nghiên cứu thuộc các bài báo và các đề tài nghiên cứu khoa học $[1,4,5], \ldots$ Vì vậy trong báo cáo này, tác giả sẽ không trình bày các kết quả hiệu chỉnh và kiệm định mô hình nữa mà trình bày các kết quả chính của nghiên cứu dự báo, cảnh báo ngập lụt cho ven biển Thái Bình gây ra bởi nước dâng và sóng lớn trong bão.

\section{a. Mô phỏng ngập lụt ven biển Thái Bình trong bão thật}

Với trường hợp cơn bão trong thực tế đổ bộ vào khu vực, tác giả chọn bão Damrey tháng 9 năm 2005 đổ bộ vào Nam Định, với sức gió mạnh tới cấp 10,11 . có nơi giật trên cấp 12 đổ bộ trực tiếp vào ven biển các tỉnh Thái Bình, Nam Định, Ninh Bình, Thanh Hóa, Hải Phòng vào rạng sáng ngày 27 tháng 9 đã gây vỡ đê biển Nam Định làm nước biển tràn vào sâu trong đất liền. Do không ghi nhận được số liệu quan trắc mực nước dâng cũng như độ cao ngập lụt ven bờ Thái Bình, nên trong báo cáo này tác giả lựa chọn số liệu quan trắc tại trạm đảo Hòn Dấu và Hòn Ngư (nơi có số liệu quan trắc gần khu vực nghiên cứu nhất) để so sánh với kết quả tính toán từ mô hình. Trên hình 3 là so sánh biến thiên mực nước quan trắc với nước dâng tính toán trong bão Damrey tại Hòn Dấu và Hòn Ngư theo 2 phương án có và không xét tới ảnh hưởng của sóng biển. Kết quả cho thấy, về xu thế kết quả tính toán từ mô hình tương đối phù hợp với biến thiên mực nước quan trắc. Về giá trị, với phương án có tính đến ảnh hưởng của sóng mô hình cho kết quả tính toán gần đúng với giá trị quan trắc hơn so với phương án không xét đến ảnh hưởng của sóng, phần đóng góp của nước dâng do ứng xuất sóng là khoảng hơn $20 \mathrm{~cm}$ tại thời điểm bão đổ bộ vào bờ. 


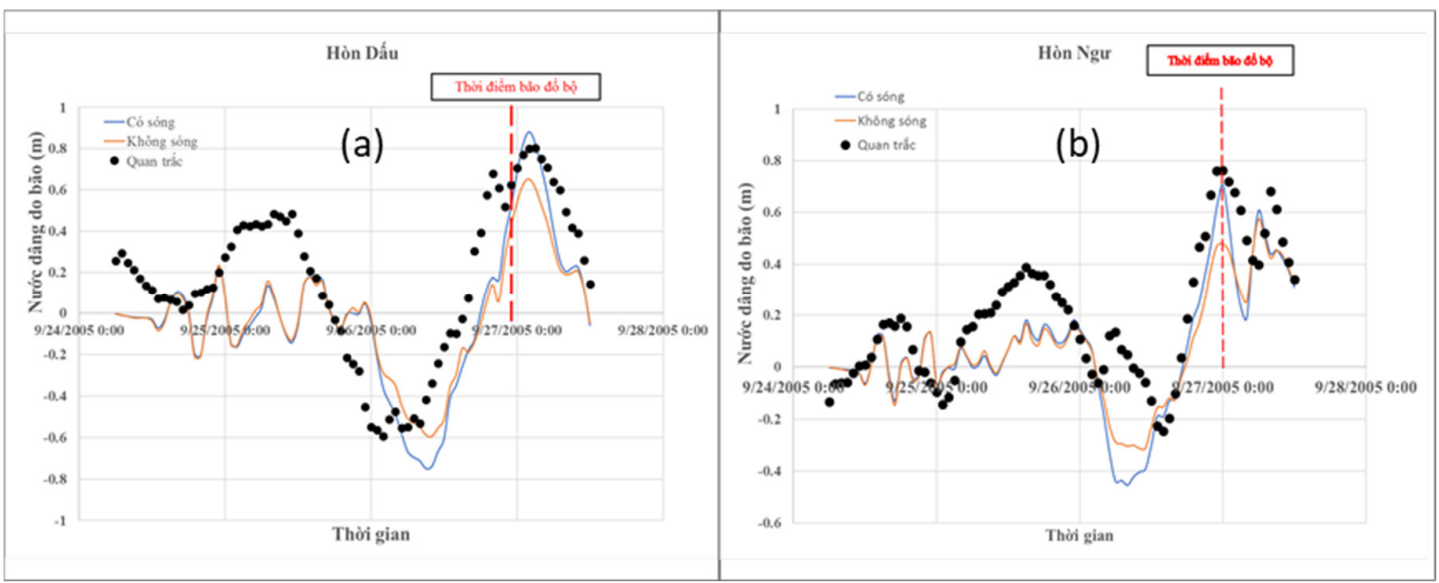

Hình 3. So sánh biến thiên mực nước quan trắc với nước dâng tính toán trong bão Damrey (9/2005) tại Hòn Dấu (a) và Hòn Ngư (b) theo phương án có và không xét tới ảnh hưởng của sóng.

Trên hình 4 là phân bố ngập lụt do bão Damrey tại ven biển Thái Bình theo phương án không $(4 a)$ và có $(4 b)$ xét tới ảnh hưởng của sóng. Trong đó, cả 2 trường hợp đều được tính tới ảnh hưởng của thủy triều thực tại khu vực trong quá trình bão đổ bộ. Do bão Damrey gây nước dâng chưa thể tới mức tràn qua đê tại ven biển Thái Bình nên kết quả mô phỏng ngập lụt ở đây là cho trường hợp ven biển Thái Bình không có đê hoặc đê bị vỡ. Đây là phương án được lựa chọn để tính toán nguy cơ ngập lụt do nước dâng do bão tại các khu vực ven biển mà trên thế giới thường làm.

Kết quả cho thấy, với trường hợp không xét tới ảnh hưởng của sóng, nước dâng do bão kết hợp với thủy triều gây ngập với diện tích $191,759 \mathrm{~km}^{2}$. Trong trường hợp xét tới ảnh hưởng của sóng diện tích ngập lên tới $258,246 \mathrm{~km}^{2}$. Như vậy trong trường hợp xét tới ảnh hưởng của sóng, nước dâng do ứng suất bức xạ sóng đã góp phần đáng kể làm ra tăng ngập lụt tại ven biển Thái Bình trong bão Danrey.
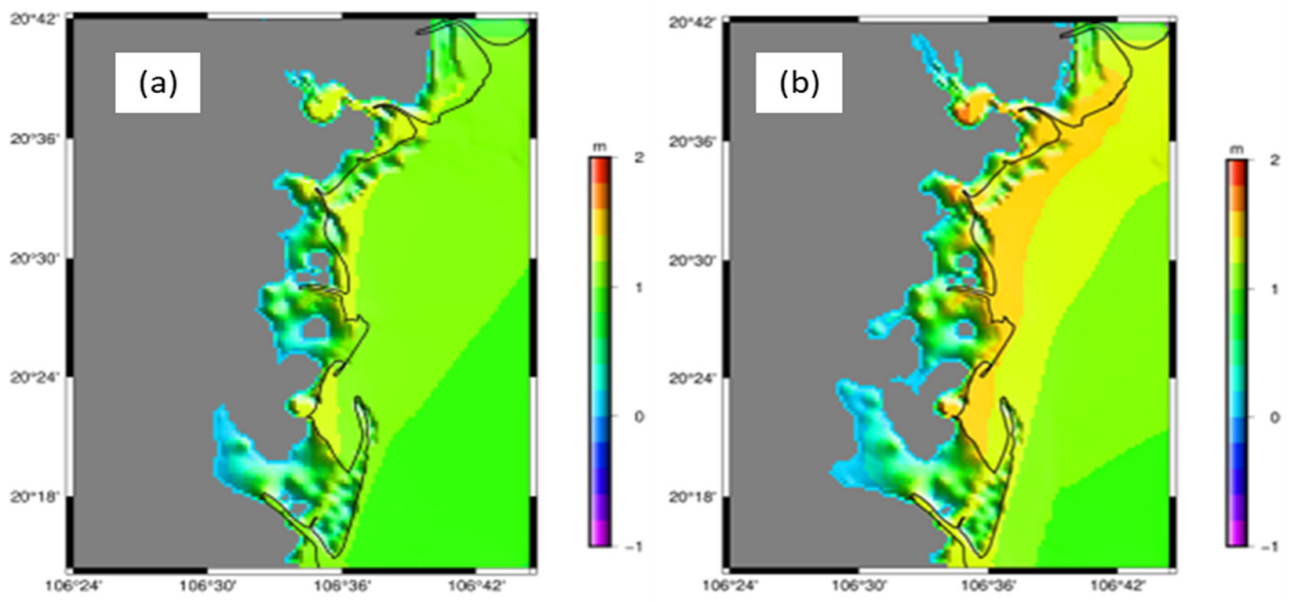

Hình 4. Kết quả mô phỏng ngập lụt ven biển Thái Bình trong cơn bão Damrey (tháng 9/2005) với trường hợp không (a) và có (b) xét đến ảnh hưởng của sóng biển.

\section{b. Mô phỏng ngập lụt ven biển Thái Bình trong bão giả định}

Như đã trình bày ở trên, trường hợp xét tới ảnh hưởng của sóng, nước dâng do ứng suất bức xạ sóng đã góp phần đáng kể làm ra tăng ngập lụt tại ven biển Thái Bình trong bão Danrey. Vì vậy tác giả sẽ lựa chọn phương án tính có xét tới ảnh hưởng của sóng để tính toán với các kịch bản ngập lụt khu vực ven biển Thái Bình theo các cấp bão đổ bộ từ cấp 10 đến cấp 12. Đây là khoảng cấp bão có có nguy cơ cao xuất hiện tại khu vực. Hướng di chuyển và 
vị trí đổ bộ được giả định sẽ gây nước dâng lớn nhất tại ven biển tỉnh thái Bình, với hướng đổ bộ trực diện và vị trí đổ bộ nằm phía Nam của tỉnh, giáp tỉnh Nam Định.

Trên hình 5 là kết quả mô phỏng ngập lụt tại ven biển Thái Bình với cấp bão đổ bộ từ 1012. Kết quả cho thấy với cấp bão càng tăng thì nguy cơ ngập càng cao. Diện tích ngập theo các cấp bão tương ứng là $263,275 \mathrm{~km}^{2}, 327,073 \mathrm{~km}^{2}$, và $417,647 \mathrm{~km}^{2}$, tương ứng với bão cấp 10,11 và 12 .
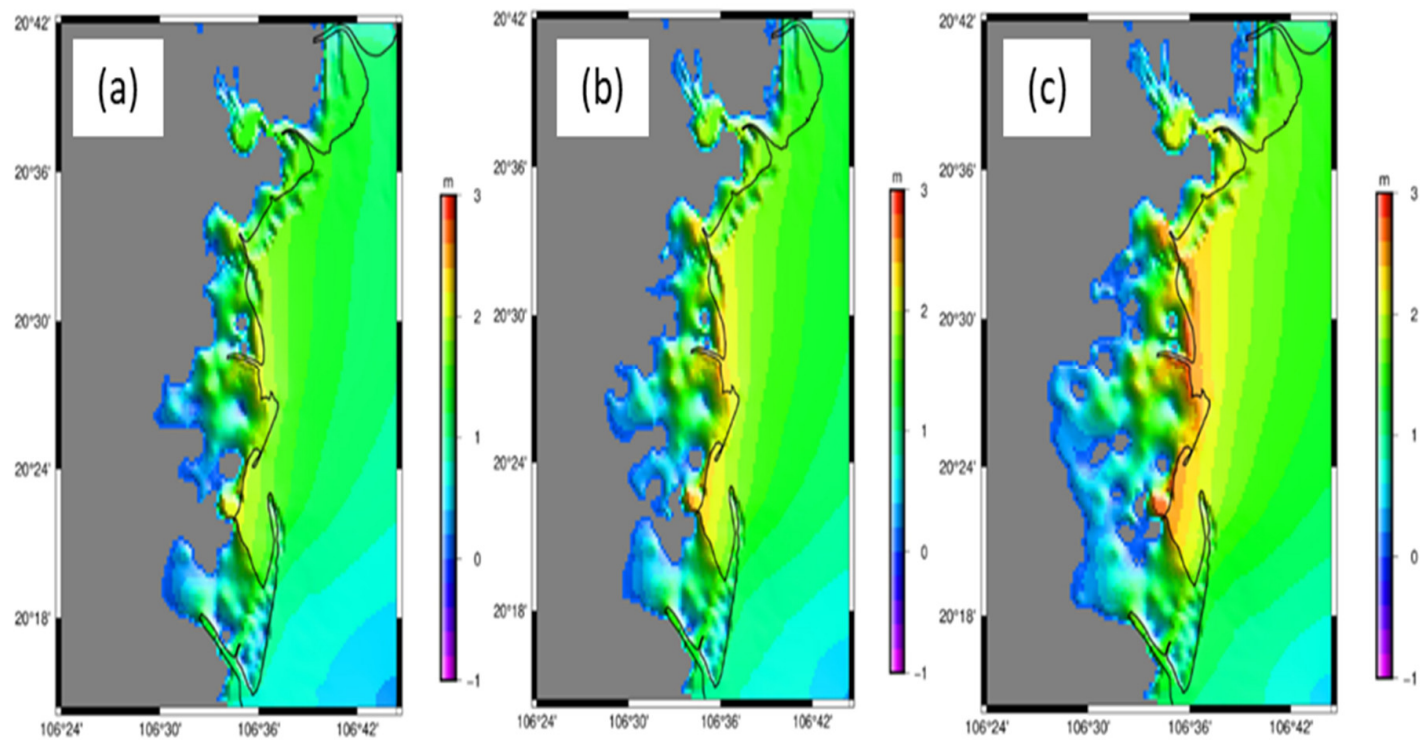

Hình 5. Kết quả mô phỏng ngập lụt ven biển Thái Bình trong cơn bão giả định cấp 10 (a), cấp 11 (b) và cấp $12(\mathrm{c})$.

Kết quả mô phỏng ngập lụt cho trường hợp bão cấp 10 đổ bộ vào khu vực với các pha thủy triều khác nhau được thể trên hình 6 cho thấy mức độ ngập tăng cùng với độ cao của thủy triều, khi bão đổ bộ vào triều cường (độ cao thủy triều $1 \mathrm{~m}$ trên mực nước trung bình thì diện tích ngập lên tới 760,378 km², gần gấp 3 lần so với trường hợp bão đổ bộ vào thời điểm thủy triều ở mức trung bình $\left(263,275 \mathrm{~km}^{2}\right)$.
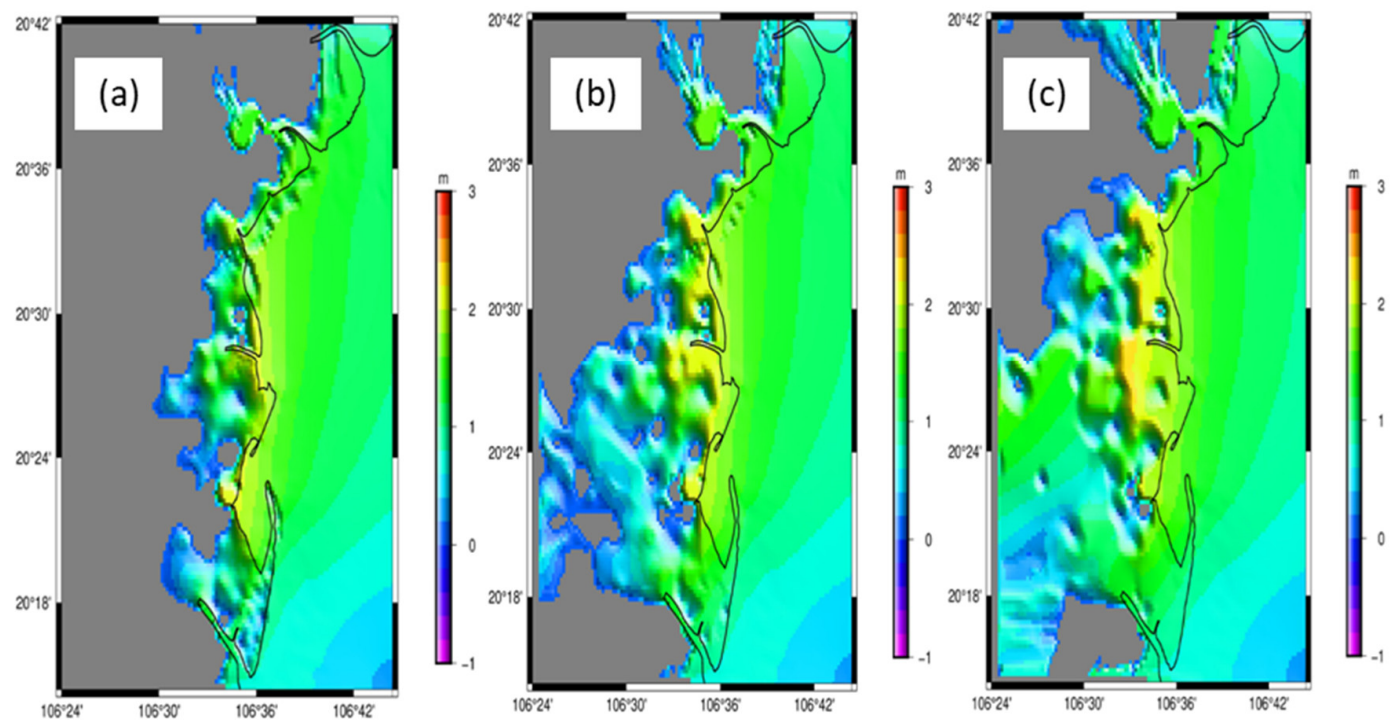

Hình 6. Phân bố ngập lụt do nước dâng bão với bão cấp 10 đổ bộ vào thời điểm mực nước triều trung bình (a), cao $0,5 \mathrm{~m}(\mathrm{~b})$ và $1 \mathrm{~m}(\mathrm{c})$. 


\section{Kết luận}

Trong nghiên cứu này, mô hình dự báo nước dâng do bão và ngập lụt ven bờ cho khu vực ven biển Thái Bình đã được xây dựng. SuWAT là mô hình tích hợp thủy triều, sóng và nước dâng do bão. Miền tính và lưới tính là lưới lồng 3 lớp, trong đó miền tính $\mathrm{D} 3$ được xây dựng chi tiết với độ phâm giải $300 \mathrm{~m}$ cho ven biển Thái Bình. Các kết quả tính toán, mô phỏng ngập lụt cho bão thực, cấp bão theo kịch bản và các pha thủy triều khác nhau đã được trình bày trong báo cáo. Một số kết quả chính của nghiên cứu như sau:

- Đã xây dựng được hệ thống lưới tính lồng 3 lớp phục vụ dự báo nước dâng do bão và ngập lụt ven bờ tại ven biển tỉnh Thái Bình bao gồm lưới tính Biển Đông, miền và khu vực với độ phân giải tăng dần tới 300m (lưới khu vực-D3) để có thể mô phỏng chi tiết ngập lụt vùng ven bờ tại khu vực.

- Đã đánh giá tương tác giữa thủy triều, sóng biển và nước dâng bão tại khu vực. Kết quả cho thấy, thủy triều chỉ có ảnh hưởng đáng kể tới nước dâng tổng cộng khi bão đổ bộ vào khu vực có biên độ triều cao tại thời điểm triều cường. Trong khi đó, sóng trong bão gây nước dâng đáng kể qua đó đề xuất phương án áp dụng vào dự báo nghiệp vụ.

- Kết quả mô phỏng ngập lụt vùng ven bờ mặc dù chưa được kiểm chứng đầy đủ nhưng cho xu thế phù hợp với các phương án tính toán. Ngoài mô phỏng ngập lụt cho trường hợp bão thực tế (bão Damrey tháng 9/2005 đổ bộ vào Nam Định), nguy cơ ngập do một số kịch bản bão đổ bộ và đổ bộ vào các pha thủy triều khác nhau cũng được mô phỏng và phân tích.

Những kết quả đã đạt được của nghiên cứu này sẽ làm cơ sở để tiến tới ứng dụng mô hình SuWAT trong cảnh báo, dự báo nghiệp vụ ngập lụt cho vùng biển ven bờ Việt Nam.

Đóng góp của tác giả: Xây dựng ý tưởng nghiên cứu: P.V.T., N.B.T.; Lựa chọn phương pháp nghiên cứu: P.V.T., N.K.C.; Xử lý số liệu: P.K.N., P.Q.H.; Viết bản thảo bài báo: P.V.T., P.K.N.; Chỉnh sửa bài báo: N.B.T., N.K.C.

Lời cảm ơn: Nghiên cứu này được hỗ trợ bởi Đề tài nghiên cứu khoa học cấp bộ Bộ Tài nguyên và Môi trường, "Nghiên cưu xây dưng hệ thống dư báo tổ hợp sóng biển cho Việt Nam phục vu phòng chống thiên tai”, mã số TNMT.2018.05.28. Tập thể tác giải xin chân thành cảm ơn.

Lời cam đoan: Tập thể tác giả cam đoan bài báo này là công trình nghiên cứu của tập thể tác giả, chưa được công bố ở đâu, không được sao chép từ những nghiên cứu trước đây, không có sự tranh chấp lợi ích trong nhóm tác giả.

\section{Tài liệu tham khảo}

1. Đăng, V.H; Thủy, N.B; Chiến, Đ.Đ; Kim, S. Nghiên cứu đánh giá định lượng các thành phần nước dâng trong bão bằng mô hình số trị. Tạp chí Khoa hoc và Công nghẹ biển 2017, 17, 132-138.

2. Mạnh, Đ.V. và cs. Phát triển và hoàn thiện mô hình dự báo sóng bão, nước dâng do bão, thủy triều cho dải ven biển Việt Nam, Báo cáo tổng kết đề tài, Viện Cơ học, Hà Nội, 2001.

3. Thủy, N.B.; Cường, H.Đ.; Tiến, D.Đ.; Chiến, Đ.Đ.; Kim, S. Đánh giá diễn biến nước biển dâng do bão số 3 năm 2014 và vấn đề dự báo. Tạp chí Khí tuợng Thủy văn 2014, $647,14-18$.

4. Sao, N.T. Storm surge predictions for Vietnam coast by Delft3D model using results from RAMS model. J. Water Resour. Environ. Eng. 2008, 23, 39-47.

5. Thuy, V.T.T. Storm surge modeling for Vietnam's coast. Nederlands, Delft Hydraulic, M.sC. Thesis H.E. 136, 2003, pp. 140. 
6. Thuy, N.B.; Kim, S.; Dang, V.H.; Cuong, H.D.; Wettre, C.; Hole, L.R. Assessment of Storm Surge along the Coast of Central Vietnam. J. Coastal Res. 2017, 33, 518530 .

7. Hien, N.X.; Uu, D.V.; Thuc, T.; Tien, P.V. Study on wave setup with the storm surge in Hai Phong coastal and estuarine region. VNU J. Sci. Earth Sci. 2010, 26, 82-89.

8. Chiến, Đ.Đ; Sáo, N.T; Thái, T.H; Thủy, N.B, Ảnh hưởng của thủy triều và sóng biển tới nước dâng do bão khu vực ven biển Quảng Bình - Quảng Nam. Tạp chí khoa hoc ĐHQG Hà Nội 2015, 31(3S), 28-36.

9. Chiến, Đ.Đ.; Thủy, N.B.; Sáo, N.T.; Thái, T.H.; Kim, S. Nghiên cứu tương tác sóng và nước dâng do bão bằng mô hình số trị. Tạp chí Khí tuợng Thủy văn 2014, 647, 2126.

10. Ngoc, P.K.; Luan, N.T.; Thuy, N.B.; Kim, S.; Dang, V.H. The impact of wave on coastal inundation. The 8th Asia-Pacific Workshop on Marine HydrodymicsAPHydro 2016, Hanoi, September 20-23. Marine Hydrodynamics and Science section 2016, pp.168-176.

11. Janssen, P.A.E.M. Quasi-linear Theory of Wind-Wave Generation Applied to Wave Forecasting. J. Phys. Oceanogr. 1991, 21, 1631-1642.

12. Kennedy, A.B.; Gravois, U.; Zachry, B.C.; Westerink, J.J.; Hope, M.E.; Dietrich, J.C.; Powell, M.D.; Cox, A.T.; Luettich, R.A.Jr.; Dean, R.G. Origin of the Hurricane Ike forerunner surge. Geophys. Res. Lett. 2011, 38, L08608, doi:10.1029/2011GL047090, 2011.

13. Funakoshi, Y.; Hagen, S.C.; Bacopoulos, P. Coupling of Hydrodynamic and Wave models: Case Study for Hurricane Floyd (1999) Hindcast. J. Waterw. Port Coastal Ocean Eng. 2008, 134(6), 321-335. doi: 10.1061/(ASCE)0733-950X.

14. Kim, S.Y.; Yasuda, T.; Mase, H. Numerical analysis of effects of tidal variations on storm surges and waves. Appl. Ocean Res. 2008, 30, 311-322.

15. Zhang, M.Y.; Li, Y.S. The dynamic coupling of a third-generation wave model and a 3D hydrodynamic model through boundary-layers. Cont. Shelf Res. 1997, 17, 11411170 .

16. Bertin, X.; Li, K.; Roland, A., and Bidlot, J.R. The contribution of short waves in storm surges: two recent examples in the central part of the bay of Biscay. Cont. Shelf Res. 2015, 96, 1-15.

17. Kim, S.Y.; Yasuda, T.; Mase, H. Wave set-up in the storm surge along open coasts during Typhoon Anita. Coastal Eng. 2010, 57, 631-642.

18. Mastenbroek, C.; Burgers, G.; Janssen, P.A.E.M. The Dynamical Coupling of a Wave Model and a Storm Surge Model through the Atmospheric Boundary Layer. $J$. Phys. Oceanogr. 1983, 23, 1856-1866.

19. Chen, Q.; Wang, L.; Zhao, H. An integrated surge and wave modeling system for Northern Gulf of Mexico: simulations for urricanes Katrina and Ivan. Proceedings of the $31^{\text {st }}$ International Conference on Coastal Engineering (Hamburg, Germany). 2008, 2, pp. 1072-1084.

20. A coupled model of Surge, Wave and Tide (SuWAT) for storm surges and waves, User manual Version 20.26, programed by Sooyoul Kim, Tottori University, Japan, 2017.

21. Kim, S.Y.; Yasuda, T.; Mase, H. Numerical analysis of effects of tidal variations on storm surges and waves. Appl. Ocean Res. 2008, 30, 311-322. 


\title{
Effect of waves during the storm on coastal inundation in Thai Binh province
}

\author{
Pham Van Tien', Pham Khanh Ngoc 2 , Pham Quoc Hung ${ }^{3}$, Nguyen Kim Cuong ${ }^{4}$, \\ Nguyen Ba Thuy ${ }^{2 *}$
}

${ }^{1}$ Institute of Energy, Ministry of Industry and Trade; phamvantienbn@gmail.com

${ }^{2}$ Vietnam National Centre for Hydrometeorological Forecasting; ngocpkchibo@gmail.com; thuybanguyen@gmail.com

3 Thai Binh Centre for Hydrometeorological; quochungkttv@gmail.com

${ }^{4}$ VNU University of Science; cuongnk@hus.edu.vn

\begin{abstract}
Waves and storm surges during the tropical typhoons are ones of the most severe natural disasters, which significantly affect on coastal structures in coastal area. Especially, when typhoon comes during high tidal level, the combination of waves, surges and tides is the cause of coastal inundation and erosion, resulting in destroying coastal constructions. Technically, coastal inundation caused by typhoon depends on the coastal topography (land and underwater), tides, storm surge and wave setup. Therefore, the effects of tides, storm surge and waves are necessary to taken into account to forecasting inundation model. In addition, the coastal topography needs to have very high resolution and to consider the sea dyke system. A coupled model of surge, wave and tide (SuWAT) developed by Kyoto University, Japan has been applied in forecasting storm surge at the Vietnam National Center for Hydro-meteorological Forecasting. In this study, the results of simulated inundation along the coastal area of Thai Binh Province during the Damrey (9/2005) typhoon are presented in wich several scenarios are performed. Based on this study, SuWAT model could be further researched on warning and forecasting inundation for coastal areas of Vietnam.
\end{abstract}

Keywords: Storm surge; Inundation; Wave setup; SuWAT. 